\title{
Realidade Virtual aplicada na proteção do meio ambiente e combate ao mosquito Aedes Aegypti
}

\author{
Leticia L. Moreira ${ }^{1}$, Daniel A. Silva ${ }^{2}$, Higor D. C. Silva ${ }^{1}$, Patrick A. R. Faria ${ }^{3}$, \\ João P. M. Pedroso ${ }^{1}$, Pedro M. de Sousa ${ }^{2}$ \\ ${ }^{1}$ Instituto de Ciências Exatas e Tecnológicas - Universidade Federal \\ de Viçosa campus Rio Paranaíba (UFV-CRP) \\ Rodovia MG-230, Km 07 - CEP 38810-000 - \\ Rio Paranaíba - MG - Brasil \\ \{leticia.l.moreira, daniel.a.araujo,higor.cavalcanti\}@ufv.br \\ \{patrick.faria, joao.pedroso, pedromoises\}@ufv.br
}

\begin{abstract}
The game has the objective of social awareness, influencing intuitive and fun way to environmental protection and the fight against the Aedes Aegypti mosquito. The implementation of this project relies on the use of the Unity $3 D$ platform, a great tool that makes life easier for its users due to series of script libraries available, and as well as the C\# language. With it, the game sample was held at II Games Show on Federal University of Viçosa campus Rio Paranaiba, obtaining results that show that the game really is good at teaching children about social awareness in a simple and intuitive way. Finally, it is expected that the game is a great aid to learning tool.
\end{abstract}

Resumo. O jogo tem o objetivo de conscientização social, influenciando de forma intuitiva e divertida a proteção do meio ambiente e o combate ao mosquito Aedes Aegypti. A implementação desse projeto utiliza a plataforma Unity 3D, uma ótima ferramenta que facilita a vida de seu usuário devido a série de bibliotecas de script disponíveis, e bem como a linguagem C\#. Com isso, a amostra do jogo foi realizada na II Mostra de Jogos da Universidade Federal de Viçosa campus Rio Paranaíba, obtendo resultados que mostram que o jogo realmente é bom em ensinar as crianças sobre a conscientização social, de forma simples e intuitiva. Por fim, espera-se que o jogo seja uma ótima ferramenta de auxilio ao aprendizado.

\section{Introdução}

Não é algo recente as discussões acerca do cuidado com o meio ambiente em todas as partes do planeta Terra. Tal assunto vem sendo motivo de preocupação em países das mais diversas situações econômicas, étnicas e culturais. O acompanhamento da temperatura do planeta deu-se início do ano de 1880, desde então, nos últimos tempos o grau das mudanças climáticas apenas aumentou, motivado principalmente por fatores como poluição, desmatamento e emissão de gases, consequências de atitudes praticadas pelos seres humanos [EFE].

Várias iniciativas voltadas à proteção do meio ambiente como o Greenpeace, o Tratado de Quioto e as diversas Conferências realizadas pela Organização das Nações 
Unidas (ONU), foram desenvolvidas e defendidas ao longo dos anos, por governos de várias potências. Apesar disto, em sua maioria, ainda não são suficientes para a melhoria do problema[do Meio Ambiente ].

Não obstante, o acúmulo de lixo em quintais, lotes vagos e na rua, pode resultar em um outro fator extremamente problemático e perigoso à saúde humana que vem assolando a América Latina, principalmente o Brasil nos últimos anos. O acúmulo de água nesses resíduos, concede a oportunidade do nascimento do mosquito Aedes Aegypti, popularmente conhecido como mosquito da dengue, da zika e da chicunkunya.

Segundo [Montenegro 2016], em seu artigo publicado na Revista Isto É, o descuido da população e de autoridades brasileiras desencadeou em uma série de agravamentos no quadro de doenças transmitidas pelo mosquito e um aumento exagerado da quantidade de pessoas com dengue. O número de bebês com microcefalia, anomalia no tamanho e desenvolvimento do cérebro, aumentou consideravelmente, resultante da contaminação das mães durante a gestação pelo vírus zika. Além disto, diversas outras doenças se tornaram presentes no cotidiano dos hospitais brasileiros como a chicunkunya, cujos sintomas são semelhantes aos da dengue, porém mais brandos e a Síndrome de Guillian-Barré que afeta o sistema nervoso também causada pelo zika vírus.

Apesar de todas as ações sociais já realizadas e ensinadas acerca da problemática apresentada neste artigo como a poluição do meio ambiente e o acréscimo no número de mosquitos Aedes Aegypti, ainda há uma extrema dificuldade na conscientização da população mundial e brasileira, respectivamente. Portanto, uma das possíveis soluções existentes que venha a auxiliar neste fato, é a escolha de um público específico. Neste caso, demos preferência ao público infantil baseando-se em sua maior facilidade de absorver e colocar em prática conhecimentos e regras.

À procura de uma alternativa que forneça ao mesmo tempo diversão e aprendizado às crianças e, que acima de tudo consiga conscientizá-las das ações que devem ser realizadas, resolvemos utilizar a tecnologia ao nosso favor. Optamos então, pelo desenvolvimento de um jogo digital. Com uma história bastante didática e divertida, tal jogo possui como personagem principal um super-herói que precisa combater mosquitos transmissores e realizar a limpeza do meio ambiente, chamando a atenção das crianças ao decorrer da fase devido ao entretenimento e, consequentemente ensinando sobre as questões sociais.

A ação extensionista deste, é o desenvolvimento e a implantação de um jogo, inicialmente no ambiente escolar e infantil de Rio Paranaíba. Tal ação é de extrema importância por conseguir levar além de diversão, conhecimento ao nosso público-alvo. Uma outra questão a ser ressaltada é o fato de que o jogo conseguirá proporcionar à população infantil de Rio Paranaíba, um contato maior com a tecnologia, fato este que nem sempre acontece no dia a dia dos pequenos.

\section{Computação Gráfica}

O termo computação gráfica começou a ser implementado por volta dos anos sessenta. A princípio, tal tecnologia era voltada principalmente para empresas e indústrias de diversos ramos, como automobilísticas e aeroespaciais. Entretanto, com o passar do tempo, e difusão da tecnologia, a computação gráfica passou a estar presente em quase todas as 
áreas de conhecimento do ser humano. Computação Gráfica (CG) é uma área da Ciência da Computação que se dedica ao estudo e desenvolvimento de técnicas e algoritmos para geração (síntese) de imagens através do computador [Manssour 2006]. Com a utilização da CG tornou-se possível uma maior interação entre o homem e o computador, pois a geração de imagens possibilitou a simulação de quase todas as atividades do ser humano. A Computação Gráfica, assim como diversas outras tecnologias abrange diversas áreas de conhecimento humano, desde a arte até a psicologia. Quando falamos especialmente neste jogo a ser desenvolvido, podemos observar duas áreas em destaque: lazer e educação. A primeira ocorre devido o projeto ser um jogo e, a segunda por abranger a conscientização ambiental e conhecimento sobre o vírus Aedes Aegypti. Por fim, função da computação gráfica nesse projeto é ajudar na educação de pessoas sem o conhecimento prévio do assunto, atraindo o jogador pelo aspecto visual, junto com o roteiro. Dessa forma, demonstra ser uma ferramenta de grande importância na conclusão desse trabalho.

\section{Metodologia}

A metodologia, consiste no desenvolvimento do ambiente, do banco de dados, e por fim no relacionamento entre o conteúdo social e o próprio jogo, demonstrando da melhor forma possível todas as questões que deverão ser discutidas e ensinadas às crianças.

\subsection{Projeto}

Várias são as ferramentas utilizadas para o desenvolvimento de tal jogo, como o mouse, teclado, monitor e caixas de som. Além disto, todos estes dispositivos auxiliam também a interação com o usuário que o está utilizando.

\subsection{Implementação}

A implementação do projeto em questão, utiliza a plataforma Unity 3D bem como a linguagem C\#. A Unity 3D consiste basicamente em um game engine que permite que seu usuário desenvolva jogos de uma maneira mais simples e fácil. Isto ocorre pois ela já possui uma série de bibliotecas de script embutidas, fazendo com que o usuário não precise programar uma variedade de componentes. Além da portabilidade e de todas as outras vantagens que já possui, um ponto extremamente forte da Unity é a sua capacidade de utilizar elementos criados por outros desenvolvedores como áudios, scripts pré-prontos, texturas, entre outros.

\subsection{Implantação}

Pretende-se alcançar a opinião não apenas das crianças, mas também de seus pais e professores, procurando saber sobre a familiaridade deles em relação a utilização da plataforma pelo seus filhos e alunos dentro da sala de aula ou em casa. Portanto, tal atividade necessita que haja investimentos em computadores nas escolas, a fim de que as crianças possam ter acesso a essa ferramenta.

\subsection{Avaliação}

O jogo e seus aspectos e características foram desenvolvidos a partir de materiais, os quais são fornecidos pelo próprio site da Unity. A avaliação do jogo será realizada por meio de questionários distribuídos no ambiente de avaliação levando em consideração a usabilidade da ferramenta, bem como sua eficácia e funcionamento. 
V Congresso Brasileiro de Informática na Educação (CBIE 2016)

Anais dos Workshops do V Congresso Brasileiro de Informática na Educação (CBIE 2016)

Desse modo, de acordo com os resultados obtidos, será realizada a manutenção e melhoria da ferramenta caso seja necessário, bem como sua permanência.

\section{Funcionamento}

Nomeado de 'A Saga do Zicão - a preservação ambiental significa um compromisso com a vida', o jogo possui como principal propósito, um ambiente dividido em duas fases, as quais deverão ser cumpridas pelo personagem principal do projeto desenvolvido. $\mathrm{O}$ jogo funcionará da seguinte forma: inicialmente haverá uma tela de Menu, representada pela figura 1, para que o usuário possa escolher a opção que preferir, sendo elas: Jogar, Opções, Créditos e Instruções.

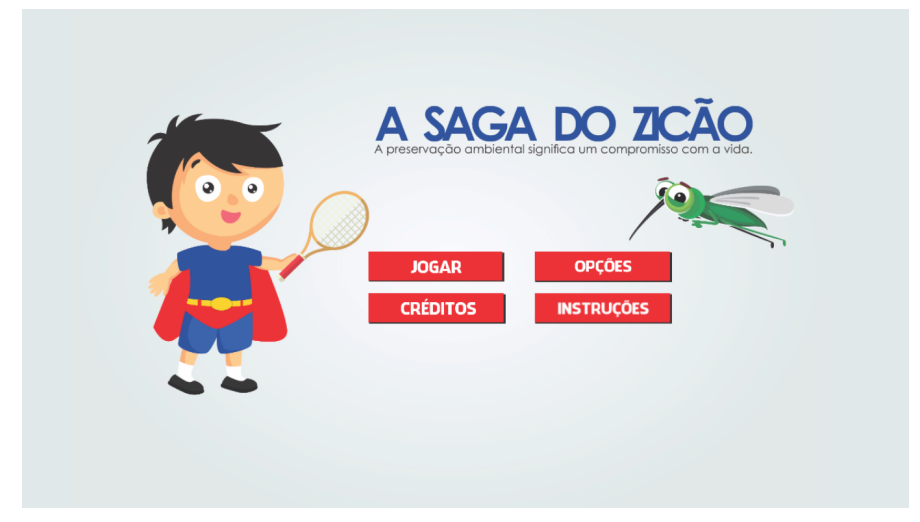

Figura 1. Menu do jogo

Quando o usuário selecionar a opção "Jogar"no Menu, ele será levado direto para o mapa do jogo em questão (Figura 2), onde ele poderá caminhar em direção a fase que irá jogar. Após esta escolha, o usuário será redirecionado para a tela de introdução (Figura 3), a qual explicará uma história sobre o descuido da população quanto a lixos jogados nas ruas, em sua maioria tóxicos e nocivos à saúde, bem como a quantidade excessiva de mosquitos Aedes Aegypti. Desse modo, um garoto resolve virar um super herói, salvando o mundo de todas essas ameaças ao redor da sociedade humana praticando ações sociais que auxiliem neste aspecto.

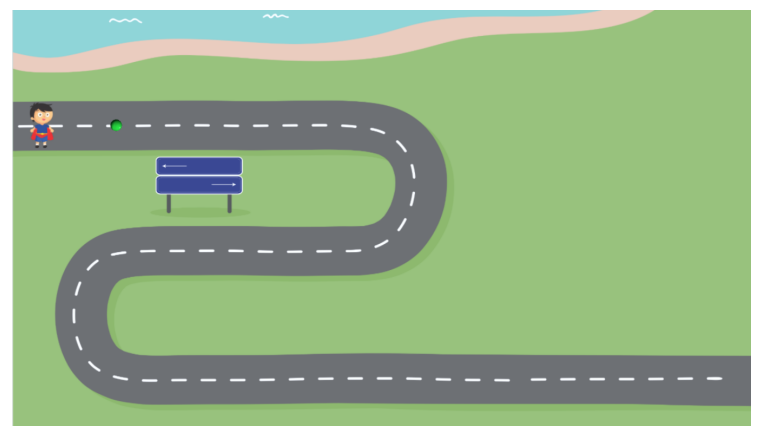

Figura 2. Mapa do jogo 
V Congresso Brasileiro de Informática na Educação (CBIE 2016)

Anais dos Workshops do V Congresso Brasileiro de Informática na Educação (CBIE 2016)

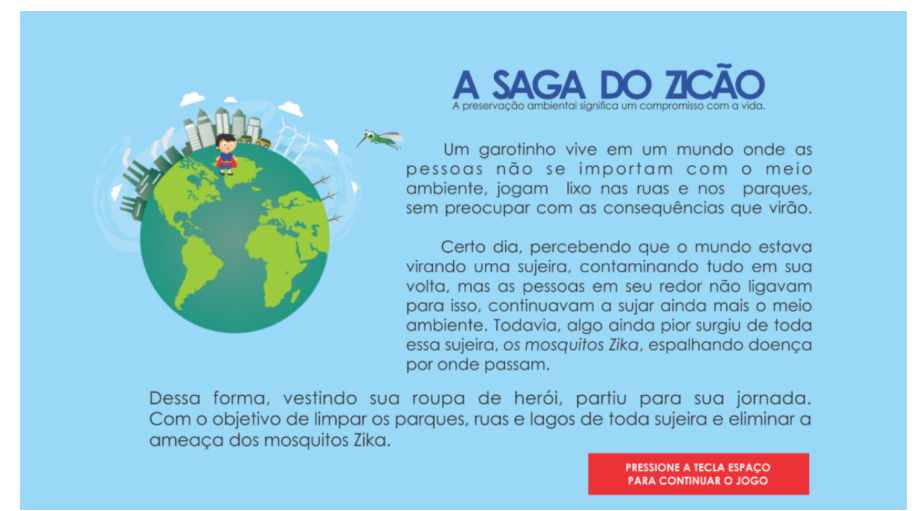

Figura 3. Tela de Introdução

Após a tela de introdução, o usuário poderá ir direto para o jogo em questão. A primeira fase do jogo, representada pela figura 4, gira em torno de um principal objetivo que é recolher todos os lixos que estão no local, fugindo do mosquito Aedes Aegypti, nomeado de Zicão.

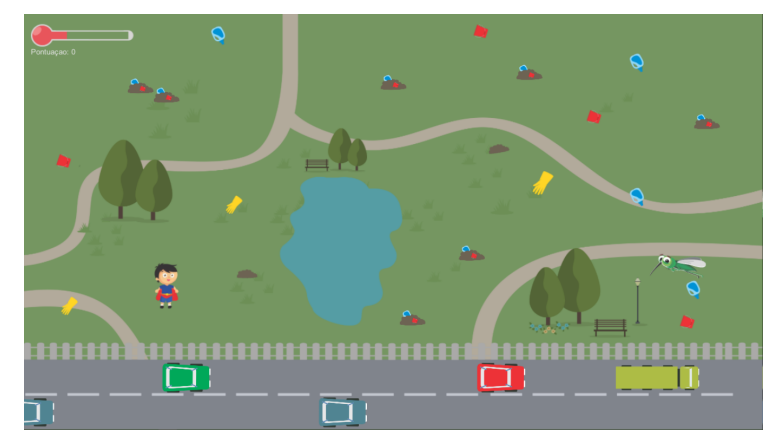

Figura 4. Cenário do game

Deve-se levar em consideração que, a cada quinze segundos, aparece um mosquito novo que persegue o personagem principal, como pode ser visto na figura 5 . No canto esquerdo superior do jogo há um termômetro representando as vidas que o personagem possui. A cada vez que ele é atingido por um mosquito, sua temperatura aumenta, fazendo com que ele fique doente. Quando o termômetro atingir sua temperatura máxima, o personagem morre e jogo termina.

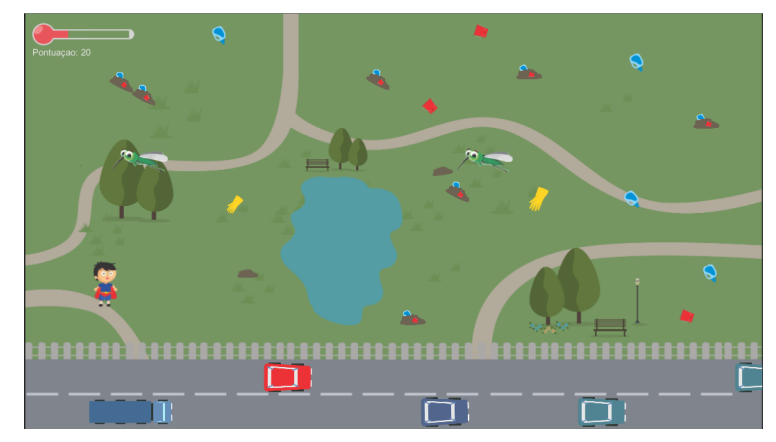

Figura 5. Ataque dos mosquitos 
V Congresso Brasileiro de Informática na Educação (CBIE 2016)

Anais dos Workshops do V Congresso Brasileiro de Informática na Educação (CBIE 2016)

Caso a criança/usuário vença o jogo, ou seja, consiga recolher todo o lixo da tela sem que sua temperatura aumente muito devido a colisões com os mosquitos, ela será redirecionada para uma tela de aprendizado, onde haverá um ensinamento/curiosidade sobre o meio ambiente (Figura 6).

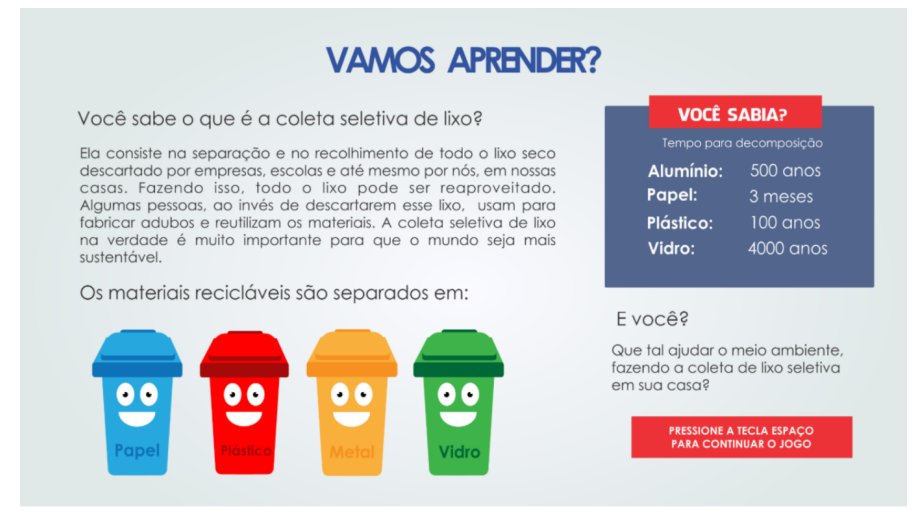

Figura 6. Tela de ensinamento

Caso contrário, o jogo será finalizado em uma tela de game over (Figura 7).

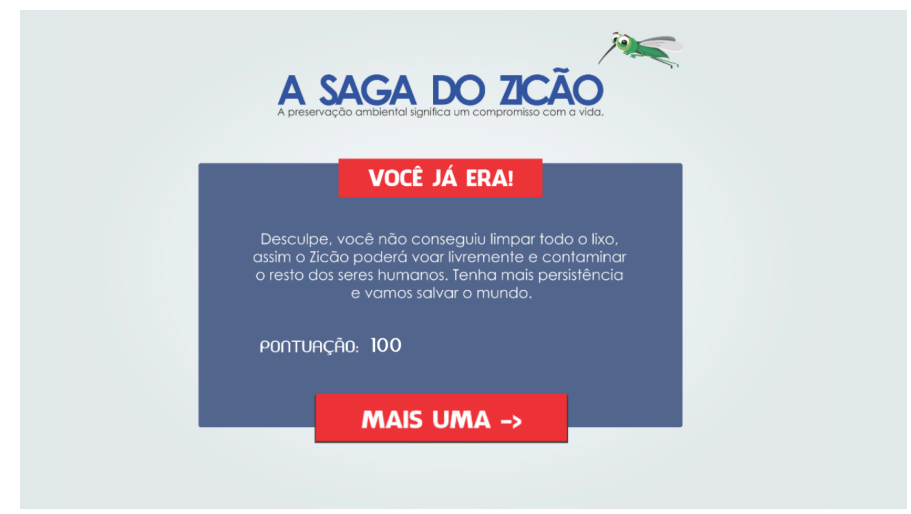

Figura 7. Tela de game over

$\mathrm{Na}$ segunda fase do jogo, representada pela Figura 8, o usuário basicamente precisará fazer as mesmas ações que realizou na primeira fase, com a diferença de um bônus que ele ganhará por ter completado a primeira fase com sucesso. 
V Congresso Brasileiro de Informática na Educação (CBIE 2016)

Anais dos Workshops do V Congresso Brasileiro de Informática na Educação (CBIE 2016)

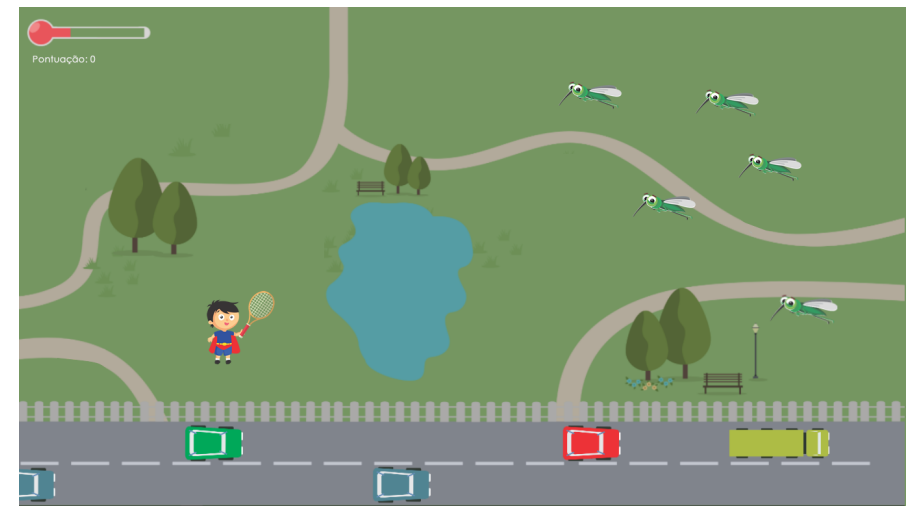

Figura 8. Segunda fase

\section{Resultados}

O jogo foi apresentado na II Mostra de Jogos Digitais ocorrida na Universidade Federal de Viçosa campus Rio Paranaíba a fim de se obter melhor um conhecimento sobre a opinião de alunos, orientadores e professores. Além de fazer uma breve experimentação do jogo, cerca de cem pessoas responderam a um questionário formado por vinte e uma perguntas, as quais era exatamente direcionadas à satisfação do aluno quanto ao jogo. As imagens 9, 10 e 11 representam o grau de satisfação dessas pessoas em algumas perguntas realizadas.

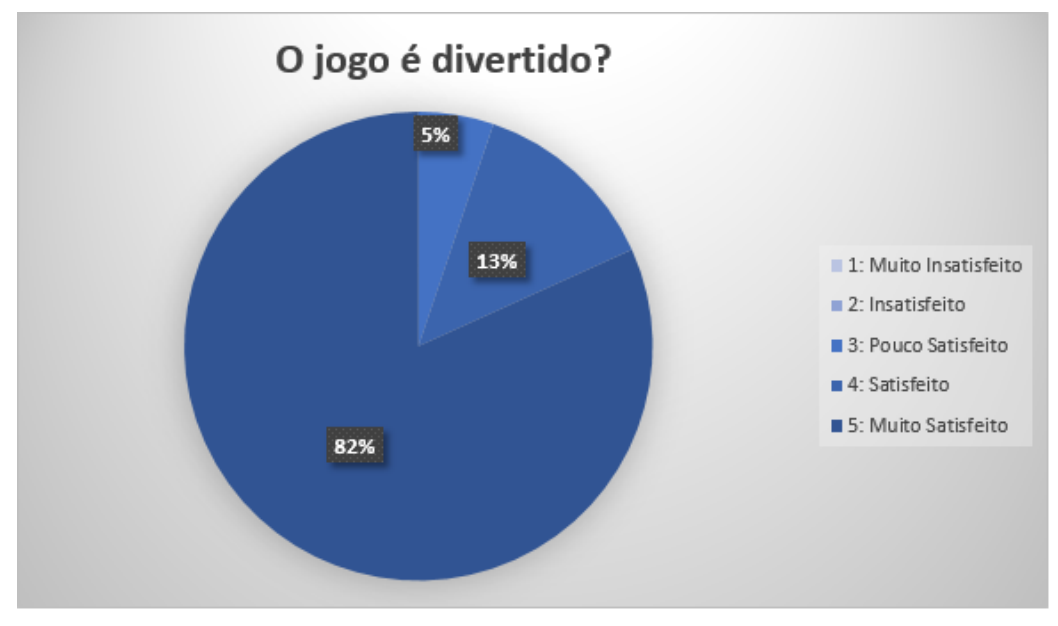

Figura 9. 0 jogo é divertido? 
V Congresso Brasileiro de Informática na Educação (CBIE 2016)

Anais dos Workshops do V Congresso Brasileiro de Informática na Educação (CBIE 2016)

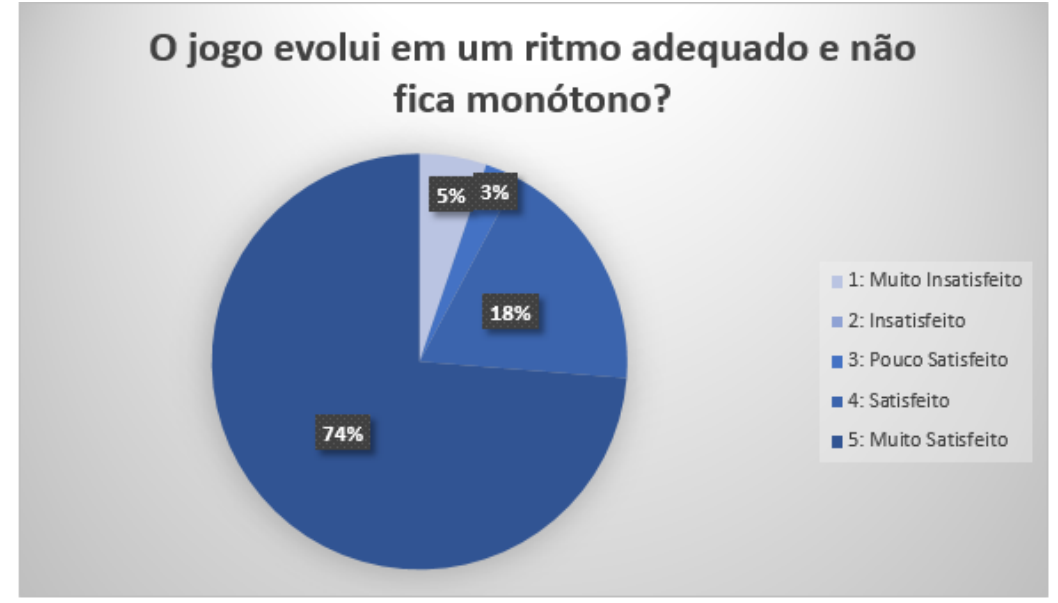

Figura 10. 0 jogo evolui em um ritmo adequado e não fica monótono?

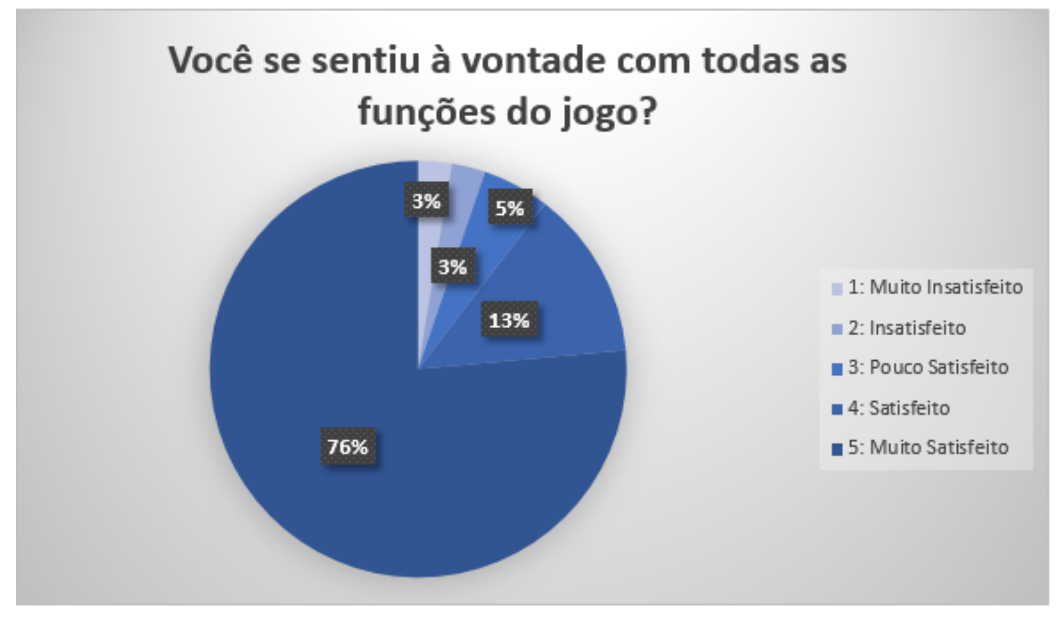

Figura 11. Você se sentiu a vontade com todas as funções do jogo?

\section{Conclusão}

Conclui-se que, ao mesmo tempo que o projeto une o entretenimento da criança com sua aprendizagem, ele também encadeia uma série de ações extensionistas. A aplicação da ferramenta no ensino de um assunto, que às vezes se torna complexo e maçante quando ensinado da forma tradicional, pode fazer com que a criança se envolva mais e, consequentemente aprenda mais.

Além disso, espera-se que, com este jogo, as crianças percebam a importância de cuidar e de se preocupar com o meio ambiente. Se atentando que o aprendizado nem sempre precisa ser algo, teórico e cansativo, mas que pode ser, acima de tudo divertido e extrovertido.

Por fim, espera-se que o jogo não substitua o professor, mas que seja uma ferramenta de auxílio ao aprendizado de tudo que foi ensinado na sala de aula.

\section{Referências}

Adami, A. Realidade virtual. 
V Congresso Brasileiro de Informática na Educação (CBIE 2016)

Anais dos Workshops do V Congresso Brasileiro de Informática na Educação (CBIE 2016)

Braga, M. (2001). Realidade virtual e educação. Revista de biologia e ciências da terra, $1(1): 1-13$.

do Meio Ambiente, M. Protocolo de quioto.

EFE, R. Temperatura da terra em 2014 foi a mais alta em 135 anos.

Jacobson, L. (1994). Realidade virtual em casa. Rio de Janeiro, Berkeley.

KIRNER, C. (2008). Evolução da realidade virtual no brasil. In X Symposium on Virtual and Augmented Reality, pages 1-11.

Malaquias, F. F. d. O. (2012). Realidade virtual como tecnologia assistiva para alunos com deficiência intelectual. $\mathrm{PhD}$ thesis.

Manssour, Isabel Harb Cohen, M. (2006). Introdução à computação gráfica. RITA, 13(2):43-68.

Montenegro, R. (2016). Um mosquito cada vez mais perigoso, pages 40, 45. Revista ISTOÉ.

NETTO, ANTONIO VALERIO Machado, L. d. S. a. O. M. C. F. d. (2002). Realidade virtual: Definições, dispositivos e aplicações. Tutorial. Revista Eletrônica de Iniciação Científica da SBC, II, 2.

Oculus. Site oficial oculus.

Sousa, R. P. d., Moita, F. d., Carvalho, A. B. G., et al. (2016). Tecnologias digitais na educação.

Trindade, Jorge Fiolhais, C. (2000). A realidade virtual no ensino e na aprendizagem da física e da química. Gazeta da Física, 19(11). 